\title{
Fighting Through Fiction
}

\author{
Helen King
}

Published online: 29 October 2013

(C) Springer Science+Business Media New York 2013

As the Call for Papers for this Special Issue observed, and as medicine and the medical humanities have increasingly acknowledged, we are narrative creatures. In 1999, in a 'Discussion point' feature in the journal Social History of Medicine, David Harley (1999, p. 407) set out the case for a 'rhetorical turn' in the history of medicine, recognising that 'diagnosis, therapy and prognosis... are usually interactive processes and the efficacy of medical interventions therefore depends upon meaning, narrative and persuasion'. The rhetoric of healing creates confidence in the patient, and the expectation of a cure. In the following year, first Paolo Palladino (2000) and then Ivan Crozier responded to Harley, Palladino negatively, Crozier (2000, p. 542) more positively, but concluding that the social construction of medicine goes beyond rhetoric: 'Rhetoric is fundamental, but it is not the end of the story'. Since that debate, the history of medicine has to some extent given way to the broader 'medical humanities', and 'rhetoric'-with its implications of knowledge claims as contested social constructs-has been replaced by a more general interest in an apparently more neutral 'narrative'.

Narrative is simply how human brains like to think, arranging apparently random and thus disturbingly meaningless events into patterns which reveal a purpose or move towards a resolution, and which create the central character as winner, loser, or survivor, as hero or as villain. John Green's (2012) novel about young cancer patients, The Fault in Our Stars, opens with an 'Author's note' on the power, and indeed the necessity, of narrative:

This is not so much an author's note as an author's reminder of what was printed in small type a few pages ago: This book is a work of fiction. I made it up.

\footnotetext{
H. King $(\bowtie)$

Classical Studies, The Open University, Buckinghamshire, UK

e-mail: helen.king@open.ac.uk
} 
Neither novels nor their readers benefit from attempts to divine whether any facts hide inside a story. Such efforts attack the very idea that made-up stories can matter, which is sort of the foundational assumption of our species.

I appreciate your cooperation in this matter. ${ }^{1}$

This need for narrative applies to the stories we tell to ourselves as much as to those we read or see. In The Fault in Our Stars, Hazel—as a young girl with a very uncertain future - is delighted to enjoy reading a novel that turns out to be the first in a long series, commenting 'it was exciting to live again in an infinite fiction' (Green 2012, p. 46).

Illness, whether it affects our bodies or our minds, can challenge our sense of a coherent self, and when this happens we need to retell our story to incorporate new material while keeping a sense of progress: ideally, 'living happily ever after'. Close reading, perhaps the methodology most central to the humanities, is also fundamental to narrative medicine, as well as recalling the attention to reading the signs of the body that has been part of medicine since the Hippocratic corpus. The papers in this Special Issue, by practitioners and by cultural historians, address a range of aspects of narrative medicine; its place in US health care today; the range of metaphors available to patients and physicians; the morality of disability; the story of survivorship and alternatives to it; the role of dreams and what they have been thought to show about the relative powers of the mind and the body; and, above all, the ways in which specific genres within film, television, and literature have addressed disability and illness.

As is now recognised, medicine has always drawn on a range of powerful images to explore the experiences of disability, illness, and healing. For much of western history, storms, and shipwreck have been particularly potent metaphors. Travel, like illness, was a dangerous process. In the second century AD Aelius Aristidesunrivalled as the most famous patient of antiquity, and who had himself nearly been shipwrecked (Sacred Tales 2, 48.12) —described health as a brief period in a safe harbour, away from the storms of life (Sacred Tales 46.1; Petsalis-Diomidis 2010, p. 233). In the seventeenth century, a woman in labour who trusted a young and poorly trained midwife could be compared 'to an unadvised passenger, that will hazard his safety with a Pilot, that never went a sea voyage, but, by reading of books, or crossing the Thames, or some small river, makes himself a Pilot' (Willughby [c. 1672], 1863, pp. 72-73). In the first example, the patient is himself the sea vessel: in the second, the patient entrusts herself to the physician, who will guide her through the dangerous ocean waters. In narrative medicine, the metaphors have often been provided by the physician and, while some papers in this collection that take their inspiration from contemporary medicine suggest that the patient is being expected to take an ever greater role in choosing the dominant metaphor for her story, Johanna Rian and Rachel Hammer-writing from their own medical practice-present a shared model in which patient and physician create narrative in partnership, sharing a raft and navigating to health. Their paper ends with a quotation about how we cannot 'stop the raging storm'. In what may strike readers

\footnotetext{
${ }_{1}$ I owe this reference to Annie Mason.
} 
as a very optimistic model of co-authorship of an illness narrative, however, they do also accept the inherent inequality of the partners here.

Perhaps the most important source for metaphors of healing in modern western medicine is the battlefield; the 'war on cancer', the 'magic bullet', and so on. In The Fault in Our Stars the narrator, Hazel, comments on her weekly Support Group: 'And then began the circle jerk of support: everyone talking about fighting and battling and winning and shrinking and scanning' and observes that there were 'battles won amid wars sure to be lost' (Green 2012, pp. 5, 11). Another character challenges the battle imagery as follows: 'Some war,' he said dismissively. 'What am I at war with? My cancer. And what is my cancer? My cancer is me. The tumors are made of me... it is a civil war...' (Green 2012, p. 216).

Another contributor to this Special Issue, the oncologist Mark Lewis, chooses to focus on another contemporary story, this time told through the medium of television, that transforms such imagery: 'Breaking Bad'. He places the language specific to the central character Walter White's cancer-malignancy, invasion, attack, greed, destruction-in the long history of these militaristic images of medicine and locates the emergence of this narrative in the more aggressive cancer treatments made possible by both surgery and chemotherapy becoming more radical since the nineteenth century. Like Brandy Schillace, who argues that the Victorian representation of trauma as somehow able to 'cure' mental disturbances emerged as a result of new surgical techniques, he looks at the effect of changes in medical practice on metaphor and narrative. Schillace shows how writers of fiction were influenced by debates in science and medicine, with literature and science asking the same questions about human behaviour and the nature of the mind, and dealing with similar issues of perception, motivation, identity and the agency of the individual.

Agency is important in considering what metaphors make for a 'good' and potentially healing narrative. Lewis looks at a particular story told to, and sometimes embraced by, patients: the 'fighter' story, for which he identifies a modern shift from the doctor as the warrior, to the patient as the one who fights. In 'Breaking Bad', Walt White chooses to refuse cancer treatment in favour of quality of life, and Lewis contrasts White's development from his diagnosis, to becoming a manufacturer of street drugs (ostensibly to raise money to support his family), and then a violent murderer, with the Livestrong movement's presentation of the person with cancer as a 'warrior and winner'. Lewis shows that both images of the patient have something in common; a focus on the individual's power to decide on the direction the story will take.

Lewis also makes some valuable points about the identity of 'survivor' which, as he points out, may only be a temporary phase before recurrence or death. What is it to be a 'survivor'? This is an issue also addressed by Green's The Fault in Our Stars, where Hazel's boyfriend Augustus has apparently been cured of his osteosarcoma, and repeats several times the comment 'I'm on a roller coaster that only goes up' (Green 2012, pp. 11, 218, 225). How does an individual change her story to incorporate this stage, and how does she demonstrate the socially correct conclusion that the experience of cancer has somehow made her a 'better' person? To someone familiar with the classical world, this again recalls Aelius Aristides, who made sense of his multiple illnesses, and his recovery from them, as an 
opportunity to become even closer to his god, Asklepios. In early modern Europe, too, disease could be seen as positive; the 'rod of God' chastising the sinner into repentance, and thus providing evidence that the sinner was not yet beyond redemption.

Demonstrating that the metaphor of battle predated heroic surgery or chemotherapy, Aelius Aristides himself combined storms and warfare, talking about 'doing battle with the storm' (Sacred Tales 2.59; Petsalis-Diomidis 2010, p. 116). Other metaphors, such as 'the journey', described by Thomas Cole (1992, p. xxxii) as 'among the most pervasive themes in world literature' and perhaps most influenced by the model of Homer's Odyssey, incorporate the underlying theme of a 'purpose' and thus may provide more scope to ditch the baggage of winning or losing that comes with battle imagery. Rian and Hammer's paper picks up Susan Sontag's image of the individual with dual citizenship between the kingdom of the well and the kingdom of the sick, while the patient 'Allison' uses travel as what she revealingly calls her 'current working metaphor' (my italics).

Rian and Hammer address this question of finding the right metaphor. After providing a useful survey of the rise of arts in healthcare and the place of narrative therapy in the US and UK, including in physician education, and giving some personal reflections on narrative medicine in process at the Mayo Clinic, they focus on the disability memoir, The Little Locksmith, written by Katherine Butler Hathaway (1890-1942) and first published a year after her death. The dominant metaphor for healing here is of fixing a house, but Hathaway did not just use the metaphor to understand her condition; she actually bought and repaired a large house. So this is more than metaphor, it is also agent; her transformation of the house, made against her family's wishes, makes her more like Walt White in her use of illness to become someone very different from the person she had thought she was, what others saw as 'poor little Katherine'.

Walt White resists metaphor, Katherine Butler Hathaway makes metaphor reality; but is it possible to have a narrative entirely without metaphor? Susan Sontag's Illness as Metaphor (1978) pleaded for a way of being ill that was purified of metaphor; what, she asked, if the patient doesn't want to 'fight' or to go on the 'journey'? Green's characters show similar resistance; he notes in a discussion of The Fault in Our Stars that he has read Sontag, and states that 'Metaphor is part of reality. Metaphor is an exploration of the nature of reality'. 2 The character Augustus, described by his friend Isaac as being 'a bit too enamored with metaphor' (2012, p. 134), is also able to see through 'metaphoric' and 'literal' language used by others; for example the prayer of the leader of the Support Group, 'Lord Jesus Christ, we are gathered here in Your heart, literally in Your heart...' is countered by Augustus with 'I thought we were in a church basement' (Green 2012, pp. 14, 16). Hazel says that one of the things she finds attractive about Augustus is that he 'points out incorrect uses of literality' (Green 2012, p. 19). In this Special Issue, Lewis's image of 'collateral damage' - the toll placed on the body of the patient by violent therapies - usefully raises the issue of how far the patient can resist both the

\footnotetext{
${ }^{2}$ http://johngreenbooks.com/questions-about-the-fault-in-our-stars-spoilers/\#end. Accessed 12 October 2013.
} 
dominant mode of therapy and the dominant metaphors. Hathaway's metaphor/new reality was resisted by her family; Rian and Hammer seem unhappy about those who resist co-constructing a narrative with their physician. Even the notions of purpose or destination in the journey metaphor may prove unhelpful to the patient; 'Perhaps... those who support and encourage the traveller on the journey should focus equally on the quality of the journey rather than where it will eventually lead them' (Fawcett and McQueen 2011, p. 10).

Several papers here examine the moral status of the disabled or ill person in literature and film. Walt White can be seen as an extreme example of this. Unlike Aelius Aristides or an early modern patient, he responds to his illness not by finding religious meaning; instead, as a chemistry teacher, he knows that 'chemistry is change' and he himself changes to become 'bad', although in the final episode of the fifth series he dies after putting as much as possible of his affairs in order. Brandy Schillace's paper, which engages very directly with narrative fiction-in particular, Dickens' Our Mutual Friend - as a way back into close reading of medical texts, looks at the physically-disabled character Jenny Wren as the 'moral centre' of this story, with the able-bodied but deviant character Eugene Wrayburn as 'morally disabled'. Only when he is struck on the head does Eugene become a moral member of society; physically diminished, but morally strengthened and thus fit for marriage. Schillace argues that a key concept here is Descartes' 'double brain', which raised the possibility of having more than one 'self'. In its mid-nineteenth century manifestations, this suggested that violent intervention-a blow to the head, a beating, or even being shot-could cure mental disorders. Only by attacking the undesirable self could the moral self regain control. By examining the morally disabled mind in the abled body, she usefully challenges both mind/body and abled/ disabled distinctions.

Bill MacLehose also turns our attention to the mind/body boundary, and in particular to the place of dreams in how it is imagined. Dreams also feature in the sports manga that is the focus of Andrea Wood's paper, Inoue Takehiko's REAL. Here, for Togawa and Takahishi, characters who come into wheelchair basketball after becoming disabled-one in an accident, the other from an amputation caused by cancer - the reader takes on their point of view by seeing their dreams, and thus coming to share in Togawa's fear of the recurrence of the cancer that took his lower leg. Recalling Schillace's paper, here too there is also a sort of split self, in which the dream self is closer to the truth.

Dreams, a particular form of narrative, have long been seen as significant in the human quest for meaning; one only has to think of the Old Testament and its accounts of the dreams of Jacob, Joseph, Daniel, and Pharaoh, while one of the powers of the prophets is that of dream interpretation (e.g. Daniel 1: 17; Genesis 41: 15-16; Numbers 12: 6). In Latin, some of these dreams occur in sleep (a somnium), others while awake (a visio). Dreams can be diagnostic, revealing disease before the patient would otherwise be aware of it; Brooke Holmes argues that because dreams in the classical world were seen as medical, dreamers would be more likely to interpret a dream as concerning the body (Holmes 2008, pp. 89-90, n. 18). Certain dream themes were assigned specific meanings to do with the fluids of the body: 
'Fruitless trees signify corruption of the human seed' and 'Impure streams indicate disturbance of the bowels' (Regimen IV 90).

But what is a dream? In the early modern period, dreams and semi-conscious states were discussed within the context of the revival of physiological approaches to the body (Stafford 1991). The Hippocratic treatise Regimen IV described how the soul (Gk psychê) is obedient to the body while the body is awake, getting on with the various tasks the body sets it to do; while the body is engaged in activity, the mind (Gk dianoia) is not independent. But when the body is resting during sleep, the psyche 'looks after her own household and of herself performs all the acts of the body', being able to hear, see, walk, touch, feel pain, and think (Regimen IV 86). This suggests that the psychê can be responsible for the liminal activities on which MacLehose concentrates; the activities of sleepers, in particular sleepwalking or sleepfighting.

What does it mean to fight in one's sleep? In Regimen IV, some dreams replicate what was done while the body was awake; these are good dreams and signify health. But dreams that are different from what really happened in the day, and which involve struggle, indicate disturbances in the body, and should be seen as showing that the body should be treated to heal the disturbance (Regimen IV 88). Seeing strangely-shaped bodies which are frightening to the dreamer means he has eaten something unusual, while dreams of fighting show that the fluids of the body are not moving properly (Regimen IV 103).

But MacLehose's sleepers are not just dreaming of fighting: they actually do it. In another treatise from the Hippocratic Corpus, On the Sacred Disease, when the writer is describing the various alarming and inexplicable things that can happen in illness but which are not popularly labelled as coming 'from the gods', he mentions those who groan or choke in their sleep, and those who 'dart up and rush outside, being delirious until they wake' (1). Later in the treatise he returns to those who jump out of bed in terror in the night and rush outside, saying that the popular interpretation - a form of narrative-is that 'Hecate is attacking or the heroes are assaulting them' (4). For the ancient author, the organ responsible for all these and more is the brain (17). Shouting out at night is due to the brain being too hot, caused by a terrifying dream (18). Sleepwalking or sleepfighting, then, could be seen as divine in origin, but the medical interpretation suggests that the brain is not functioning properly.

Sleepwalking or sleepfighting are certainly not 'normal', and thus in the narrative approach to the body must mean something. In the 1985 film that forms the centre of Jamie McDaniel's paper, Phenomena, one of the elements that marks the character of Jennifer as 'strange' is that she sleepwalks. McDaniel describes how horror films traditionally enforce normalcy by associating disability with monstrosity or moral superiority; Phenomena takes a third route, focusing not on the disability but on who labels it as such, and whether the person so labelled accepts the label. In a fine example of exploring cinematic language, McDaniel shows how the genre of the horror film has its own conventions and techniques to direct the viewer, here serving to marginalise the 'disabled' character, Jennifer. But do either Jennifer's sleepwalking or her ability to understand insects constitute a disability? Is she demon-possessed, sick, deviant, disabled, or simply different? In this horror film, 
she is not the 'monster' - that role is taken by Patua, the son of one of the school officials, and his external appearance again raises the question of whether physical deformity must also mean moral deformity. There are useful points of connection here with Wood's chapter, as she discusses how manga uses close up and 'camera' angles but also shows how comics and graphic novels allow more time than films do for the reader to engage with a visual image.

Another theme that comes out in MacLehose's paper is the idea of a 'typical patient' and how this in turn relates to the theory underlying the medical description. Sleepfighting involves the elite male; rather than simply walking in his sleep, he rides his horse and imagines battle. This recalls Mary Wack's excellent study of love sickness (Wack 1990), a book rooted in exemplary manuscript research, which argued that 'heroic' love (amor heros or amor heroes) crept into texts in around $1100 \mathrm{AD}$ from an error in transcribing Constantine the African's eros (love). Within a century it was then firmed up so that 'heros' was firmly established; as a result of this textual shift, the most likely sufferers were seen as being "noble men who on account of wealth and the softness of their lives are more likely to suffer from this disease' (1990, p. 202). From this, new narratives were generated; because it was heroic, and thus a disease of men, and affected those at the top of society, it must be located at the top of the body, in the brain. Women could not suffer from anything 'heroic' and instead their most characteristic disorder was located at the bottom of the torso: suffocation arising in the womb. MacLehose's time frame is very similar to that of Wack's 'heroic love' and, as with that disorder, the sufferers were thought to be male and aristocratic. Gender is a feature of Schillace's approach too, as she examines the gendered manifestations of moral insanity, such as 'emotional' men or 'assertive' women. Wood's discussion of sports manga also explores gender, and demonstrates the construction of masculinity in Japanese culture, alongside the relative invisibility of the disabled male body. Togawa used to have a 'feminine' appearance but once he began to take part in sports his body became more 'masculine' and he was accepted by his peers; his loss of a leg to osteosarcoma thus challenged the basis of his masculinity. Gender as a category of analysis could have been pushed more in other papers; for example, Rian and Hammer are talking about a woman's writing, so is there any sense in which the dominant house metaphor is gendered?

The battles of the sleeping male aristocrat recall the metaphor of illness as something to be 'fought' and 'defeated'. Winning and losing does not only happen in battle, of course. In Andrea Wood's discussion of sports manga, Togawa takes up wheelchair basketball to regain a purpose in life, but his older teammate Tamura questions whether winning in wheelchair basketball has any point, as it is not visible in the media in the same way as the able-bodied sport. Visibility is another of the main themes of this collection; disabled people have historically been displayed to the public but have also been socially invisible. The same could be said of the mentally ill, particularly in the era of Bedlam as entertainment. Wood usefully discusses the role of The Stare, as abled people look at, but do not engage with, the disabled characters. The readers of the manga receive the stares of those who are looking at Togawa, and who act as mirrors of the reader while that reader simultaneously identifies with Togawa as recipient of The Stare. McDaniel 
discusses The Gaze, and one of the many benefits of bringing these two papers together is that it challenges the reader to think again about the different modes of viewing disability and illness.

Finally, the narrative approach in many of the papers presented here involves a challenging engagement with the reader or viewer. What would we do, if we were in the position of the characters with whom narrative encourages us to identify? In $R E A L$, none of the characters with disabilities was born with these, and the fact that they have to adjust to a new body presumably helps the abled reader to engage with their experience. The third central character has survived a traffic accident but is suffering from PTSD - his disability is not visible in the way that those of other characters are, and so the reader also has to think about how to respond to what is not written on the body. The papers presented here should make us consider how far we can enter into another's story, as well as how far we can rewrite our own story and take control of it. In a finite life, the appeal of 'an infinite fiction' is enormous, and the pull of narrative remains powerful simply because we are human. As Green's 'Author's Note' and the novel it introduces demonstrate, 'made-up stories can matter'.

\section{References}

Cole, Thomas $\mathrm{R}$

1992 The Journey of Life: A Cultural History of Aging in America. Cambridge: Cambridge University Press.

Crozier, Ivan

2000 Social Construction in a Cold Climate. Social History of Medicine 13: 535-546.

Fawcett, Tonks N, and Anne McQueen, eds.

2011 Perspectives on Cancer Care. Oxford: Wiley-Blackwell.

Green, John

2012 The Fault in Our Stars. Harmondsworth: Penguin.

Harley, David

1999 Rhetoric and the Social Construction of Sickness and Healing. Social History of Medicine 12: 407-435.

Holmes, Brooke

2008 Aelius Aristides Illegible Body. In Aelius Aristides between Greece, Rome, and the Gods. William V. Harris and Brooke Holmes, eds., pp. 81-113. Leiden: Brill.

Palladino, Paolo

2000 And the Answer is ... 42. Social History of Medicine 13: 147-152.

Petsalis-Diomidis, Alexia

2010 Truly Beyond Wonders: Aelius Aristides and the Cult of Asklepios. New York: Oxford University Press.

Sontag, Susan

1978 Illness as Metaphor. New York: Farrar, Straus and Giroux.

Stafford, Barbara

1991 Body Criticism. Imagining the Unseen in Enlightenment Art and Medicine. Cambridge, MA: MIT Press.

Wack, Mary

1990 Lovesickness in the Middle Ages. The 'Viaticum' and its Commentaries. Philadelphia, PA: University of Pennsylvania Press.

Willughby, Percival

1863 Observations in Midwifery, H. Blenkinsop, ed. Warwick: Cooke. 